\title{
Optical coherence tomography of the vitreoretinal interface in macular hole formation
}

\author{
V Tanner, D S Chauhan, T L Jackson, T H Williamson
}

\begin{abstract}
Aims-To image the vitreoretinal interface and provide further information on the pathogenesis of idiopathic macular hole formation.

Methods-Prospective recruitment of 80 eyes of 41 consecutive patients referred with a diagnosis of idiopathic full thickness macular hole (FTMH) to a teaching hospital retinal clinic. Both eyes of each patient underwent optical coherence tomography (OCT) imaging with vertical and horizontal scans centred on the fovea.

Results-A total of 30 eyes had stage 2 or 3 FTMHs and, of these, 21 had persistent vitreofoveal attachment and associated prefoveal opacities. 18 prefoveal opacities were identified by Goldmann contact lens examination and confirmed on OCT examination. Three prefoveal opacities were identified only on OCT examination. 10 eyes had stage 4 FTMHs and four cases were identified in whom the OCT appearance was consistent with impending, aborted, or lamellar macular holes.

Conclusions-The wide range in OCT appearance of macular holes and associated prefoveal opacities suggests that, in at least some cases, a significant amount of retinal tissue is torn from the foveal area during macular hole formation. OCT imaging provides additional information on macular hole pathogenesis and is valuable in the planning of surgical intervention.
\end{abstract}

(Br f Ophthalmol 2001;85:1092-1097)

Idiopathic full thickness macular holes (FTMH) are a relatively common cause of visual loss affecting approximately three in 1000 individuals. Those affected are characteristically female in the sixth or seventh decade of life with normal refractive errors. ${ }^{1}$ Following the first reports of success in the surgical treatment of this condition, ${ }^{23}$ there has been increased interest in the classification, pathogenesis, and differential diagnosis of idiopathic senile macular holes. In 1988 Gass $^{4}$ and then Johnson and Gass $^{5}$ described a classification scheme emphasising the importance of tangential vitreous traction in macular hole development and proposing that the prefoveal opacity seen in macular holes was composed of retinal tissue. Following reports of excellent visual recovery in some patients following surgery Gass reappraised his theory to suggest that, in the majority of cases, no foveal tissue was lost from the macula and that the hole developed as a result of centrifugal photoreceptor displacement from a central dehiscence of the umbo. ${ }^{6}$

As a result of increased surgical intervention in this condition accurate preoperative diagnosis of idiopathic senile macular holes and differentiation from similar conditions have assumed greater importance. The most common lesions simulating a FTMH are epiretinal membrane with macular pseudohole, impending macular holes, and lamellar macular holes. ${ }^{7-10}$ Careful contact lens biomicroscopy is essential in differentiating FTMH from pseudoholes, but provides little information on the nature and pathogenesis of associated prefoveal opacities.

More recently, optical coherence tomography (OCT) has been used in the evaluation of macular holes. ${ }^{11}$ OCT provides a noninvasive, non-contact imaging technique capable of producing optical cross sectional images of ocular structures in vivo with a theoretical maximum longitudinal resolution of approximately $10 \mu \mathrm{m} .{ }^{13}{ }^{14}$ OCT is capable of differentiating FTMHs from pseudoholes and also provides useful anatomical information on vitreomacular relation. ${ }^{15} 16$

We present a series of eyes with impending, aborted, lamellar, or full thickness macular holes ${ }^{4}$ in which a complete posterior vitreous detachment (PVD) had not occurred. OCT examination provided additional information on the nature and pathogenesis of the vitreoretinal interaction and associated prefoveal opacities.

\section{Methods}

Eighty eyes of 41 consecutive patients referred with a diagnosis of idiopathic macular hole were prospectively recruited from a teaching hospital retinal clinic over a 12 month period. A complete ocular examination was performed on both eyes, including best corrected Snellen visual acuity measurement (VA). A diagnosis of FTMH was initially made on biomicroscopy of the macula and vitreomacular relation, and each macular hole was graded according to the classification developed by Gass. ${ }^{6}$ The WatzkeAllen slit beam test was also carried out using the Goldmann contact lens. ${ }^{17}$ A PVD was documented as being present if a complete or partial ring of glial tissue (a Weiss ring) or a definite reflex corresponding to a detached hyaloid face could be seen on biomicroscopy. Four patients referred with an initial diagnosis of FTMH were found on careful clinical and OCT examination to have macular changes consistent with impending, aborted, or lamellar macular holes.

All patients were examined using a commercially available OCT machine (OCT 2000 
scanner, Zeiss-Humphrey, San Leandro, CA, USA). OCT utilises low coherence interferometry to obtain information on tissue depth and reflectivity by analysing an $840 \mathrm{~nm}$ probe beam reflected from retinal structures and light returning from a variable reference optical delay pathway. The discrete linear signal observed anterior to the retina, and attached to prefoveal opacities, was assumed to represent the partially detached hyaloid face. ${ }^{14}$ In order to detect the faint reflectivity of the posterior hyaloid face, the incident light was used at its maximum intensity of $750 \mu \mathrm{W}$. All B-scan retinal images were composed of 100 consecutive A-scans, acquired through the centre of the macula in both vertical and horizontal orientations. The raw scans are displayed as a $500 \times$ 500 pixel matrix with the total scan depth always being $2 \mathrm{~mm}$. Therefore, although the width of the pixel varies with scan length, the pixel depth is fixed at $4 \mu \mathrm{m}$ (25 pixels $=100 \mu \mathrm{m}$ depth as shown in Fig 1). In the false coloured, cross sectional images of retina obtained, white and red represent high signal and black corresponds to a low signal. The images presented for publication are from scans between 3 and 7 $\mathrm{mm}$ long, centred on the fovea.

\section{Results}

Thirty seven patients were diagnosed as having a total of 40 FTMHs (three cases were bilateral). In this group the mean age of the 27 women and 10 men was 70.1 years (range 60-83 years). A total of 12 eyes were classified as stage 2 holes, 18 eyes as stage 3 holes, and 10 eyes as stage 4 holes. Mean duration of symptoms was 9.4 months (range 4 weeks to 3 years) and VA ranged from $6 / 9$ to counting fingers. The right eye was affected in 21 cases and the left in 19 cases. Four patients (five eyes) had impending, aborted, or lamellar macular holes.

Twenty one out of 30 eyes $(70 \%)$ with a stage 2 or 3 FTMH had an associated prefoveal

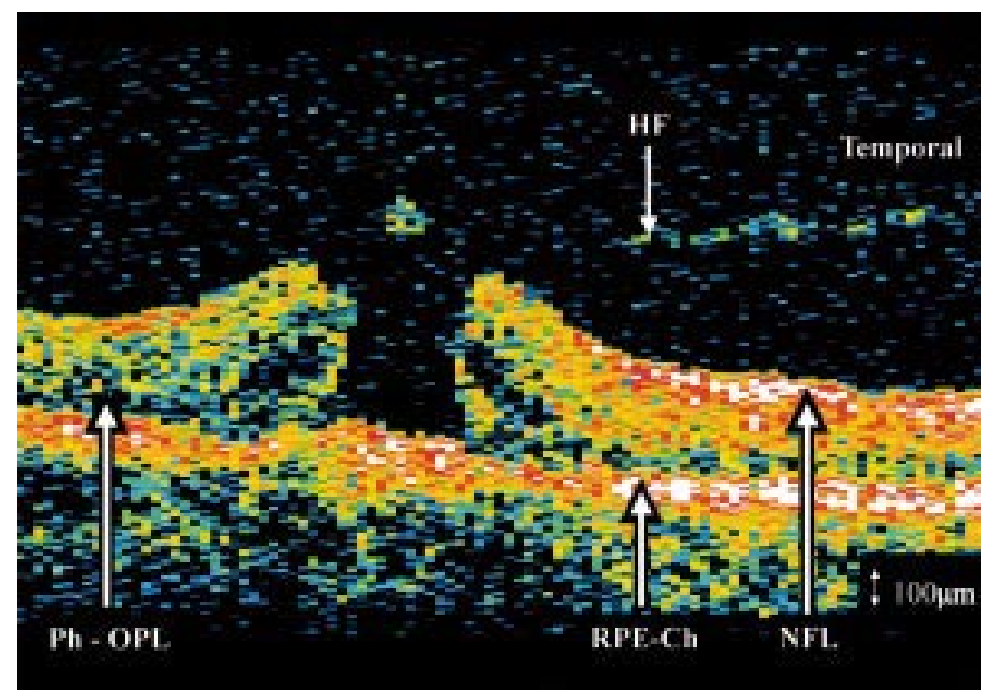

Figure 1 Case 1. Horizontal OCT scan through centre of left fovea with stage 2 macular hole and prefoveal opacity. OCT examination confirms a FTMH with a perifoveal hyaloid detachment and a small prefoveal opacity. The edges of the macular hole appear elevated because of a combination of intraretinal cyst formation and a small cuff of subretinal fluid. $H F=$ hyaloid face, $N F L=$ nerve fibre layer, $R P E-C h=$ retinal pigment epithelium and choriocapillaris, $P h-O P L=$ photoreceptors and outer plexiform layer. opacity. Eighteen prefoveal opacities were identified by Goldmann contact lens examination and confirmed on OCT examination. Three prefoveal opacities were identified on OCT examination but could not be seen on Goldmann contact lens examination. In all eyes with stage 2 or 3 FTMH a linear signal corresponding to a partially detached hyaloid face was noted on OCT, but it was not possible to identify the posterior hyaloid face using biomicroscopy. In all but one of these eyes (case 3) the detachment of the hyaloid face was most extensive on the temporal side of the hole. On OCT a variety of appearances of vitreofoveal attachment and associated prefoveal opacities was noted.

\section{FELLOW EYES}

Of 37 fellow eyes in the FTMH group, three had a FTMH, two had a complete PVD with no evidence of macular hole, and one had a complete PVD and was documented to have undergone spontaneous resolution of a stage 2 FTMH. Of the remaining 31 fellow eyes, 27 had a normal attached vitreous with no abnormality seen on OCT, one had an abnormal vitreofoveal attachment (case 5), and one had a partial thickness retinal break with persistent vitreofoveal attachment (case 8). In the remaining two fellow eyes it was not possible to perform OCT examination because of media opacity. In patients with a complete PVD no evidence of the posterior hyaloid face was seen on OCT as it occupied a position too anterior to the retina to be included in the retinal scan. In patients with a completely attached posterior hyaloid no preretinal reflectivity was seen on OCT imaging.

We present a series of cases demonstrating the many different appearances seen on OCT examination of vitreoretinal attachment and associated prefoveal opacities in various stages of macular hole formation.

\section{CASE 1. STAGE 2 MACULAR HOLE WITH SMALL} PREFOVEAL OPACITY

A 61 year old female presented with a 1 year history of decreased vision in the left eye. Snellen VA was $6 / 9$ and biomicroscopy suggested a stage 2 FTMH with a narrowing of the slit beam reported on Watzke-Allen testing (the right eye was normal with no PVD). OCT examination confirms a FTMH with a perifoveal hyaloid face detachment (Fig 1). A small prefoveal opacity is seen in continuity with the hyaloid face. The edges of the macular hole appear elevated owing to a combination of intraretinal cyst formation and a small cuff of subretinal fluid. This patient subsequently underwent pars plana vitrectomy (PPV) resulting in successful hole closure and restoration of VA to $6 / 6$.

CASE 2. STAGE 3 MACULAR HOLE WITH ATTACHED OPERCULUM

A 70 year old female presented with a 6 week history of decreased vision in the right eye. VA was $6 / 60$ and biomicroscopy suggested a stage 3 FTMH with a narrowing of the slit beam on Watzke-Allen testing (the left eye was normal 


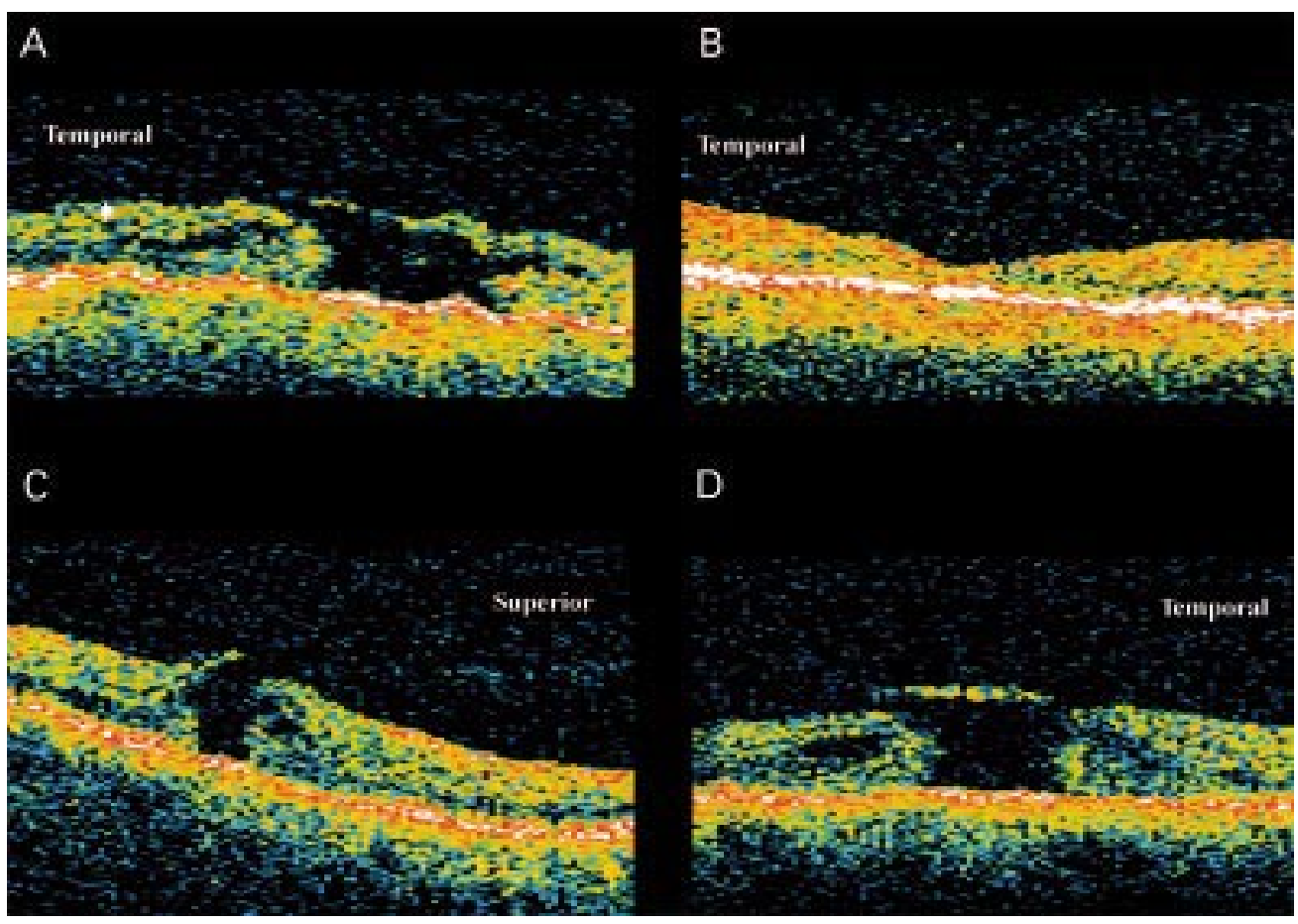

Figure 2 Case 2. Horizontal OCT scan through right fovea with stage 3 macular hole $(A)$. OCT confirms a FTMH with partially detached hyaloid face over the temporal macula, remaining attached at the hole rim, continuous with a prefoveal opacity. Horizontal OCT scan though fovea of right eye 3 months postsurgical closure of the hole (B). Case 3. Vertical (C) and horizontal (D) OCT scan through left fovea with stage 2 FTMH. OCT confirms a FTMH with partial detachment of the hyaloid face from the superior macula, remaining attached at the optic disc and inferior edge of the macular hole. A prefoveal opacity is seen in continuity with the posterior hyaloid face.

with no PVD). OCT confirms a stage 3 FTMH with partially detached hyaloid face over the temporal macula, remaining attached at the hole rim, continuous with a prefoveal opacity (Fig 2A). This patient underwent PPV combined with release of all vitreomacular traction and intraocular gas tamponade. Postoperative OCT at 3 months (Fig 2B) shows closure of macular hole and almost complete restoration of foveal architecture (VA returned to $6 / 9$ ).

CASE 3. STAGE 2 MACULAR HOLE WITH SUPERIOR HYALOID DETACHMENT AND PREFOVEAL OPACITY A 69 year old female presented with a 2 month history of decreased vision in the left eye. VA was $6 / 60$ and biomicroscopy suggested a stage 2 FTMH, with a broken slit beam reported on Watzke-Allen sign testing (the right eye was normal with no PVD). OCT confirms a stage 2 FTMH with partial detachment of the hyaloid face from the superior macula (Fig $2 \mathrm{C}$ and $\mathrm{D}$ ). The prefoveal opacity is easily identified on OCT. This case was unusual in that the hyaloid face appeared to be detaching from superiorly to inferiorly rather than temporally to nasally, as was more commonly seen. This patient subsequently underwent partially successful PPV resulting in flattening of the hole rim and improvement in VA to $6 / 24$.

CASE 4. STAGE 3 MACULAR HOLE WITH OPERCULUM

A 71 year old female presented with a 4 month history of decreased vision on the left. VA was counting fingers and biomicroscopy suggested a stage 3 FTMH with a broken Watzke-Allen sign (the right eye had a stage 4 FTMH). OCT demonstrates hyaloid face detachment temporally with persistent attachment to the prefoveal opacity (Fig 3). The prefoveal opacity is highly reflective and appears almost as thick as the surrounding retina. A vertical OCT scan taken through the centre of the macular hole (Fig 3C) gives the incorrect impression of a cyst-like space in the foveal area rather than an operculum attached to the hyaloid face. This patient subsequently underwent PPV which failed to close or flatten the macular hole.

CASE 5. ABNORMAL VITREOUS ATTACHMENT IN CONTRALATERAL EYE

Shown in Figure 4 is the asymptomatic left macula of a 67 year old male with VA of $6 / 6$ (the right eye had a stage 4 FTMH). No PVD or macular abnormality could be identified on biomicroscopy. OCT demonstrates attachment of a thin reflective signal, consistent with the posterior hyaloid face, to the fovea. The fovea is thickened with a possible early intraretinal split but no cyst formation. No change was noted in the symptoms or appearance over the 18 month follow up.

CASE 6. ABORTED BILATERAL HOLES

A 63 year old female presented with a 2 year history of small, bilateral opacities obscuring central vision and VA of 6/12 right, 6/9 left. Biomicroscopy showed an abnormal macular reflex bilaterally and no PVD. OCT demonstrates bilateral partial detachment of the posterior hyaloid face over the fovea (Fig5A and B). The hyaloid face is continuous with small areas of increased reflectivity over each fovea 


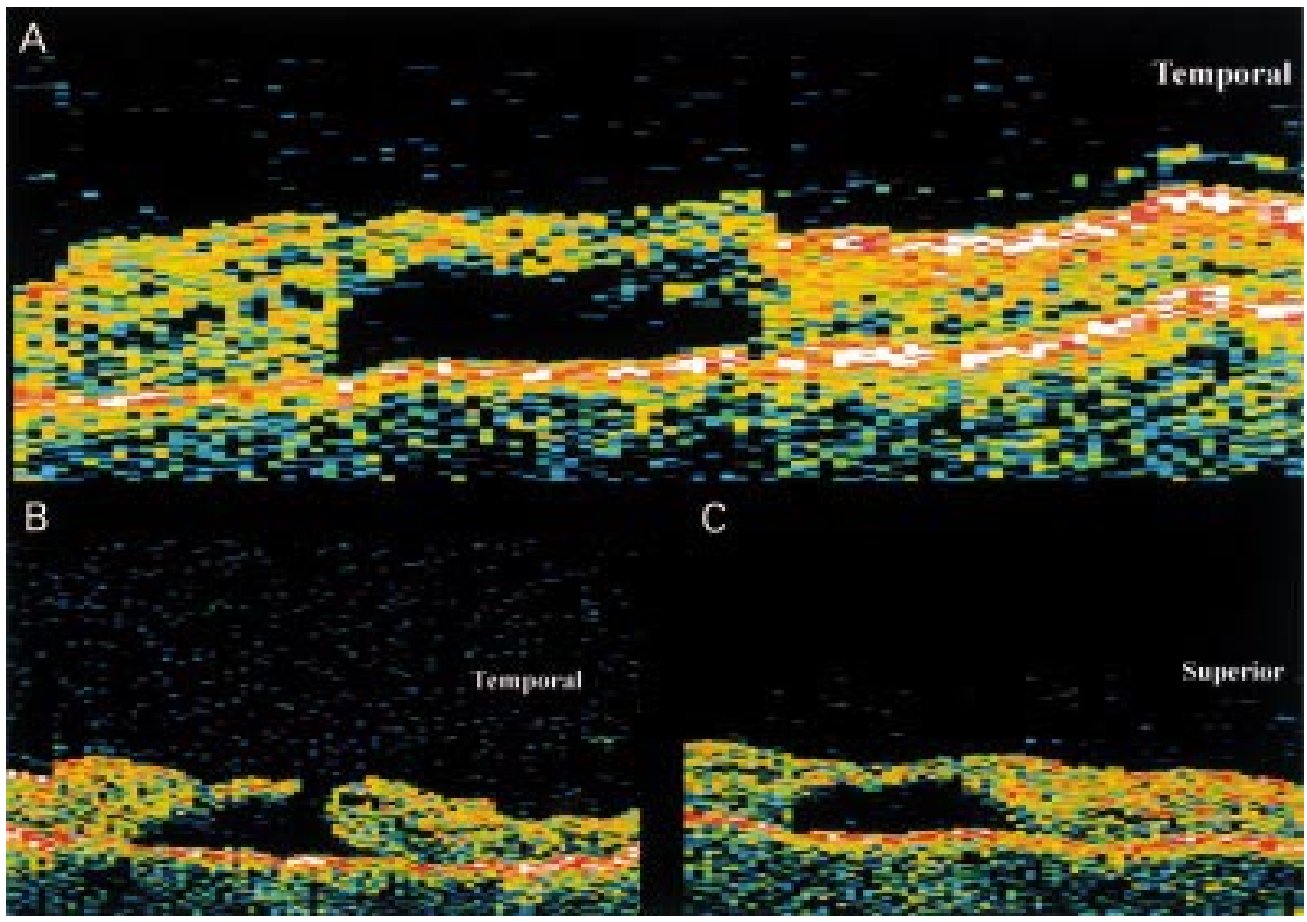

Figure 3 Case 4. Horizontal OCT scan through centre $(A)$ and just inferior to centre $(B)$ of left fovea with stage 3 FTMH. OCT demonstrates hyaloid face detachment temporally with persistent attachment to a highly reflective prefoveal opacity. (C) is a vertical OCT scan taken through the centre of the macular hole.

which are more marked on the right. Both eyes remained unchanged over 12 months follow up.

CASE 7. LAMELLAR THICKNESS MACULAR HOLE A 62 year old male presented with a 4 month history of decreased vision in the left eye. VA was $6 / 18$ and he reported a distorted rather than broken Watzke-Allen sign. Biomicroscopy suggested a stage $2 \mathrm{FTMH}$ (the right eye was normal with no PVD). OCT demonstrates a perifoveal detachment of the hyaloid face, more extensive temporally, with persistent attachment of the hyaloid face to the fovea (Fig 5C). The inner layer of the fovea is disrupted, although the outer layers remain intact, with

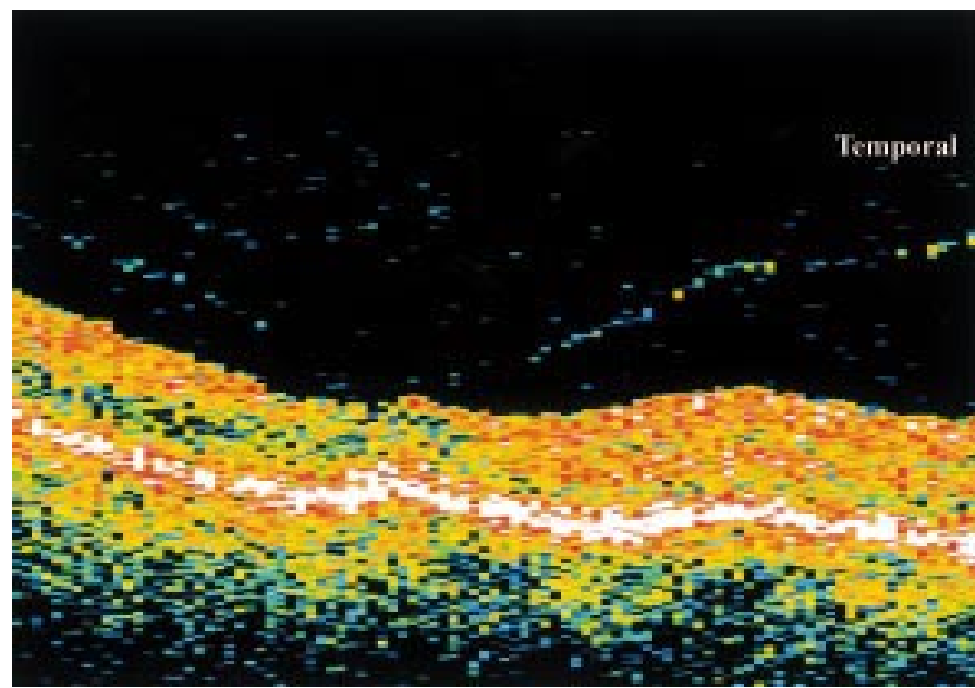

Figure 4 Case 5. Horizontal OCT scan of abnormal vitreous attachment in contralateral eye of a patient with a FTMH. OCT shows a shallow perifoveal detachment of the posterior hyaloid face with persistent attachment at the fovea. The fovea is thickened with a possible early intraretinal split. creation of a lamellar macular hole. This patient underwent PPV combined with release of all vitreomacular traction and intraocular gas tamponade. Postoperative OCT at 3 months (Fig 5D) shows restoration of foveal architecture consistent with final VA of $6 / 6$.

CASE 8. LAMELLAR MACULAR HOLE WITH PREFOVEAL OPACITY

A 73 year old female presented with a 2 month history of distorted vision in the right eye. VA was 6/9 and biomicroscopy suggested a FTMH although both the Watzke-Allen and laser aiming beam test were negative (the left eye had a stage 4 FTMH). OCT revealed a perifoveal hyaloid detachment with persistent attachment at the fovea (Fig 5E). A highly reflective prefoveal opacity is seen in continuity with the hyaloid face overlying an abnormally thin fovea, with what appears to be a partial rather than full thickness macular hole (Fig 5F, taken just inferior to $5 \mathrm{E}$ ). Over the next 9 months the hyaloid face and prefoveal opacity detached as a complete PVD leaving a slightly thinned fovea with VA of 6/9.

\section{Discussion}

OCT provides additional information on the vitreoretinal interface immediately anterior to the macula including associated prefoveal opacities. We present a series of cases demonstrating the many different appearances seen on OCT examination in the early stages of macular hole formation. These suggest great variation in the pathogenesis of prefoveal opacities and associated retinal damage during creation of idiopathic macular holes. This information may lead to a better understanding of the pathogenesis of macular holes and 


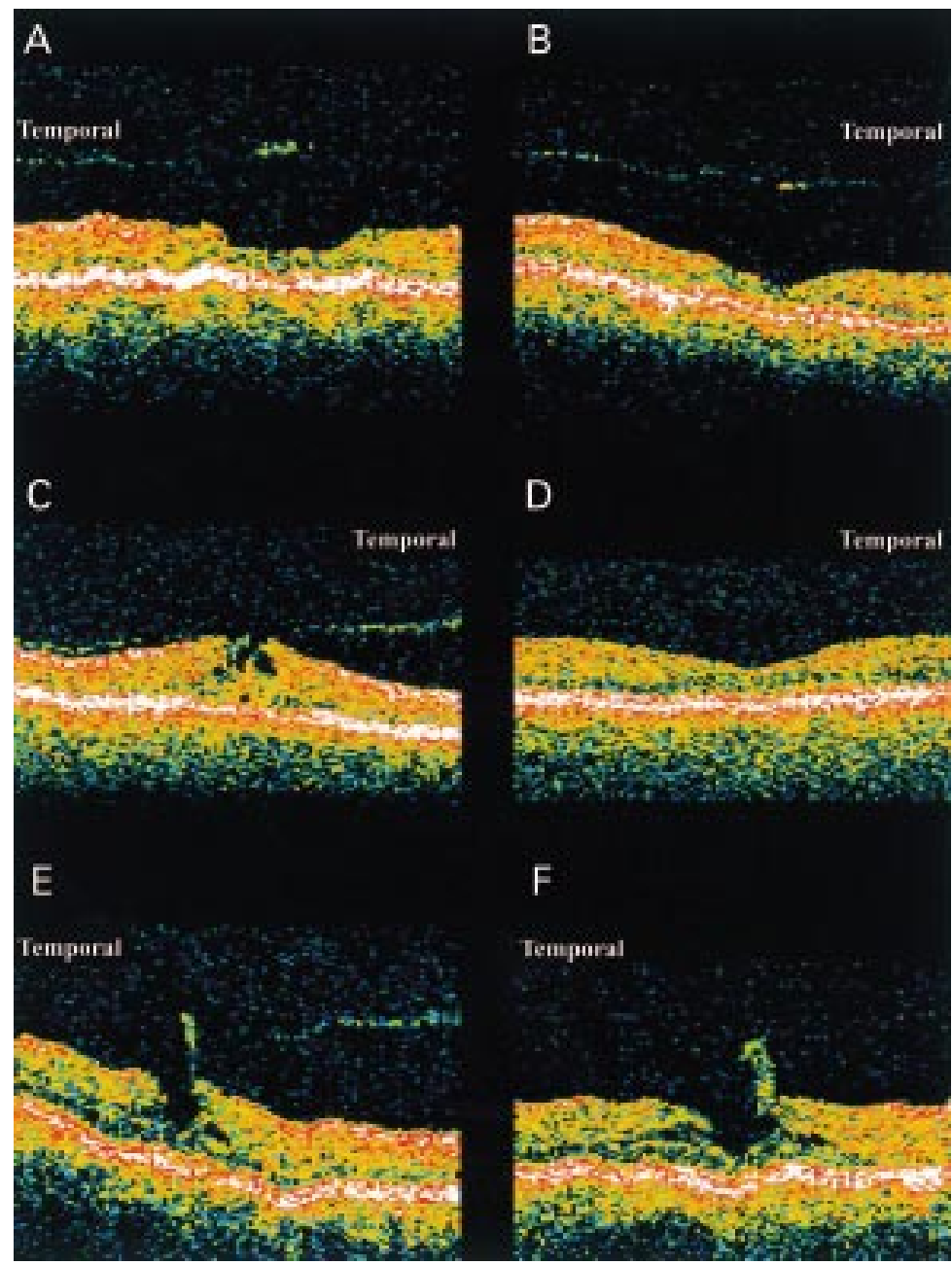

Figure 5 Case 6. Horizontal OCT scan of aborted bilateral macular holes. OCT demonstrates bilateral partial detachment of the posterior hyaloid face over the fovea, continuous with prefoveal opacities, which is more marked on the right $(A)$ than on the left (B). Case 7. Horizontal OCT scan though fovea of left eye with lamellar macular hole (C). Horizontal OCT scan though fovea of left eye 3 months post surgery (D), OCT shows restoration of foveal architecture consistent with final VA of 6/6. Case 8. Horizontal scan through centre $(E)$ and just inferior to centre $(F)$ of right fovea demonstrating a lamellar macular hole and prefoveal opacity. OCT shows a perifoveal hyaloid detachment with persistent attachment at the fovea. A highly reflective prefoveal opacity is seen in continuity with the hyaloid face overlying an abnormally thin fovea.

offer a method of determining visual prognosis following macular hole surgery.

The presence of a preretinal, high intensity, linear signal on OCT imaging of macular holes has been described previously, when it was demonstrated that the signal corresponded to the position of the posterior hyaloid face. It was suggested that the linear signal may have components derived from both the posterior vitreous face and inner limiting membrane (ILM) ${ }^{16}$ In many cases of early macular hole formation the hyaloid face appears detached from the perifoveal area but remains attached at the fovea and optic disc, suggesting a partial posterior vitreous detachment. In most cases this is difficult to observe on biomicroscopy and therefore might be described as "occult." The subtle vitreous changes in most patients with idiopathic macular hole are unlike the marked changes seen and described in vitreomacular traction syndromes. ${ }^{17}$ In case 5 of our series the OCT appearance may represent the early stages of PVD in an eye at risk of macular hole development. There is an abnormal insertion of the hyaloid face into the fovea, which we have only observed in eyes with early macular holes or contralateral eyes of pre-existing FTMH. The perifoveal hyaloid detachment, with persistent foveal detachment, suggests an element of antero-posterior (AP), vitreofoveal traction has a role in the early stages of macular hole formation.

The thickening of the hyaloid signal over some macular holes corresponds to the position of prefoveal opacities seen on biomicroscopy. The prefoveal opacities presented here probably represent a contribution from both the posterior hyaloid face and varying amounts of retinal tissue, ranging from the ILM alone to a full thickness retinal operculum. The majority of prefoveal opacities seen on OCT correspond to thickening of the posterior hyaloid face rather than full thickness retinal opercula and are represented in this series by case 1 . There appears to be minimal loss of retinal tissue and the appearance is consistent with that of a pseudo-operculum. This hypothesis is supported by description of a thinned rather than broken slit beam on Watzke-Allen testing ${ }^{18}$ and restoration of good visual function following surgical intervention. OCT findings support the concept that in most cases prefoveal opacities are composed of vitreous cortical collagen with varying amounts of internal limiting membrane, Muller cell processes, and reactive glial proliferation. ${ }^{19}$ However, case 2 represents a stage 3 FTMH with partially detached hyaloid face continuous with a prefoveal opacity. The increased signal from the prefoveal opacity on OCT examination and split-like appearance of the nasal hole edge is consistent with some tissue loss from the fovea and the prefoveal opacity containing some retinal elements.

In case 3 the prefoveal opacity is also easily identified on OCT with a much brighter signal than that of the hyaloid face. A markedly decreased VA together with reporting of a broken slit beam on Watzke-Allen testing suggests loss of retinal tissue during release of AP vitreofoveal traction and hole formation. ${ }^{18}$ This case was also unusual in that the hyaloid face appeared to be detaching from superiorly to inferiorly rather than temporally to nasally, as was more commonly seen. In case 4 , the prefoveal opacity is highly reflective, appears almost as thick as the surrounding retina, and seems to be a continuation of the retina. The appearance is consistent with significant loss of retinal tissue during hole formation and creation of the overlying operculum.

Case 6, in our series, represents bilateral aborted holes in which AP vitreofoveal traction has been released following detachment of the hyaloid face from the macula. The fovea on the right appeared thinned which, together with a decreased VA, is suggestive of disruption or loss of some retinal tissue during avulsion of the prefoveal opacities. The OCT appearance of case 7 is also suggestive of an abnormal vitreofoveal attachment with resultant AP traction causing disruption of the inner retina. 
Surgical release of vitreofoveal traction resulted in restoration of the normal foveal architecture and improvement in visual function. Case 8 demonstrates persistent hyaloid attachment to a moderately reflective prefoveal opacity that is significantly thicker than the hyaloid face itself. The fovea appears thinned with some residual tissue in the centre rather than a true FTMH. Spontaneous PVD in this case led to avulsion of the prefoveal opacity leaving a thinned fovea and moderately decreased VA. We suggest that this case represents a lamellar macular hole with loss of some retinal tissue in the overlying operculum.

Other studies have questioned the concept of a purely tangential tractional force being the pathogenetic mechanism in idiopathic macular hole formation. Ezra et $a l^{20}$ found that a significant proportion of prefoveolar opacities contained neural retinal elements, including synaptic complexes typical of cone photoreceptors, suggesting an element of AP, vitreoretinal traction in the creation of some FTMHs. These cases were also associated with a less successful initial surgical closure rate. Gass has interpreted these findings as evidence of avulsion of superficial retina (lamellar defect) and a central foveolar dehiscence in some cases of macular hole development. ${ }^{21}$ Madreperla et al also examined two macular hole opercula with transmission electron microscopy and found them to be composed primarily of Muller cells and fibrous astrocytes with no distinct retinal neuronal tissue present. ${ }^{22}$ They concluded that proliferation of fibrous astrocytes and Muller cells occurs with the formation of a macular hole and that this reparative tissue may be dislodged creating a prefoveal opacity.

Gaudric et $a l^{15}$ have recently demonstrated a perifoveal hyaloid detachment, with adherence of the posterior hyaloid to the foveal centre, in the early stages of macular hole formation similar to that seen in several of our cases. They proposed a role for AP, vitreofoveal traction in the initiation of macular hole formation followed by disruption and opening of the foveal floor to create a FTMH. Further evidence for the role of AP traction in the development of macular holes is provided by Chauhan et al using OCT $^{16}$ and Johnson et al using ultrasound imaging. ${ }^{23}$

If some FTMH are created with the loss of foveal tissue, it is likely that this group will achieve less improvement in visual acuity, and may account for some of the large variability in visual outcome following macular hole surgery. ${ }^{24}$ The potential ability to predict surgical outcome, on the basis of a minimally invasive test such as OCT imaging, may therefore allow an opportunity to target surgery on those cases with a better visual potential. It may also prevent unnecessary intervention, or alter the surgical technique, in those who are unlikely to achieve a satisfactory result. In conclusion, OCT imaging provides useful information on macular hole pathogenesis and indicates that, in a minority of cases, significant amounts of retinal tissue may be lost as a result of AP vitreofoveal traction in the creation of idiopathic macular holes.

1 Aaberg TM, Blair CJ, Gass JDM. Macular holes. Ophthalmology 1970;69:555-62.

2 Kelly NE, Wendel RT. Vitreous surgery for idiopathic macular holes. Results of a pilot study. Arch Ophthalmol
math macular holes. Res

3 Wendel RT, Patel AC, Kelly NE, et al. Vitreous surgery for macular holes. Ophthalmology 1993;100:1671-6.

4 Gass JD. Idiopathic senile macular hole. Its early stages and pathogenesis. Arch Ophthalmol 1988;106:629-39.

5 Johnson RN, Gass JD. Idiopathic macular holes. Observations, stages of formation, and implications for surgical intervention. Ophthalmology 1988;95:917-24.

6 Gass JD. Reappraisal of biomicroscopic classification of stages of development of a macular hole. Am $\mathcal{F}$ Ophthalmol 1995;119:752-9.

7 Gass JD, Joondeph BC. Observations concerning patients with suspected impending macular holes. Am f Ophthalmol 1990;109:638-46.

8 Smiddy WE, Gass JD. Masquerades of macular holes. Ophthalmic Surg 1995;26:16-24.

9 Klein BR, Hiner CJ, Glaser BM, et al. Fundus photographic and fluorescein angiographic characteristics of pseudoholes and fluorescein angiographic characteristics of pseudoholes of the macula in eyes with
mology 1995;102:768-74.

10 Fish RH, Anand R, Izbrand DJ. Macular pseudoholes. Clinical features and accuracy of diagnosis. Ophthalmology 1992;99:1665-70.

11 Puliafito CA, Hee MR, Lin CP, et al. Imaging of macular diseases with optical coherence tomography. Ophthalmology 1995;102:217-29.

12 Hee MR, Puliafito CA, Wong C, et al. Optical coherence tomography of macular holes. Ophthalmology 1995;102: $748-56$.

13 Toth CA, Narayan DG, Boppart SA, et al. A comparison of retinal morphology viewed by optical coherence tomogra1425-8.

14 Chauhan DS, Marshall J. The interpretation of optical coherence tomography images of the retina. Invest Ophthalcoherence tomography images
mol Vis Sci 1999;40:2332-42.

15 Gaudric A, Haouchine B, Massin P, et al. Macular hole formation: new data provided by optical coherence tomoformation: new data provided by optical cohe
graphy. Arch Ophthalmol 1999;117:744-51.

16 Chauhan DS, Antcliff RJ, Rai PA, et al. Papillofoveal traction in macular hole formation: the role of optical coherence tomography. Arch Ophthalmol 2000;118:32-8.

17 Gallemore RP, Jumper JM, McCuen BW, et al. Diagnosis of vitreoretinal adhesions in macular disease with optical coherence tomography. Retina 2000; 20:115-20.

18 Tanner V, Williamson TH. Watzke-Allen slit beam test in macular holes confirmed by optical coherence tomography. Arch Ophthalmol 2000;118:1059-63.

19 Gass JD. Muller cell cone, an overlooked part of the anatomy of the fovea centralis: hypotheses concerning its role in the pathogenesis of macular hole and foveomacular retinoschisis. Arch Ophthalmol 1999;117:821-3.

20 Ezra E, Munro PM, Charteris DG, et al. Macular hole opercula. Ultrastructural features and clinicopathological correlation. Arch Ophthalmol 1997;115:1381-7.

21 Gass JD. Macular hole opercula: ultrastructural features and clinicopathologic correlation. Arch Ophthalmol 1998;116: 965-6.

22 Madreperla SA, McCuen BW, Hickingbotham D, et al. Clinicopathologic correlation of surgically removed macular hole opercula. Am f Ophthalmol 1995;120:197-207.

23 Johnson MW, VanNewkirk MR, Meyer KA. Perifoveal vitreous detachment is the primary pathogenic event in idiopathic macular hole formation. Arch Ophthalmol 2001; 119:215-22.

24 Freeman WR, Azen SP, Kim JW, et al. Vitrectomy for the treatment of full-thickness stage 3 or 4 macular holes. Results of a multicentered randomized clinical trial. The Vitrectomy for Treatment of Macular Hole Study Group. Arch Ophthalmol 1997;115:11-21. 